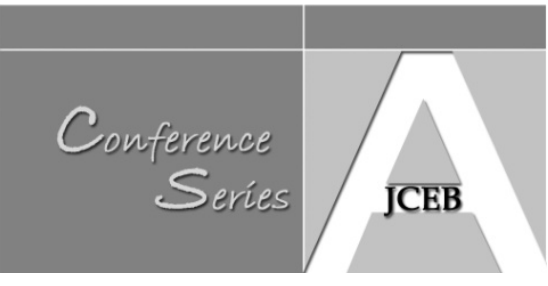

\title{
Towards the Integration of Risk and Value Management
}

Ranesh, A. Zillante, G., and Chileshe, N.

(University of South Australia, Australia)

\begin{abstract}
Governments are increasingly faced with the challenge of delivering infrastructure developments under difficult budget constraints. Public Private Partnerships (PPPs) are being used widely as a means of meeting public infrastructure demands through private finance. The aim is to achieve value for money $(\mathrm{VfM})$ through the allocation of risks to the party who can manage them more effectively. If project risks are not well managed, the project will face cost, quality and time overruns thereby affecting the viability of the project. Both Risk Management (RM) and Value Management (VM) are considered to be best practice in project management and enable organisations to define objectives when delivering complex projects whilst reducing risk and maximising value. Over the years researchers and practitioners have argued that the integration of RM and VM in a single study would avoid duplication of work and deliver better value for money thereby leading to better project outcomes. As part of an on-going doctoral study into the integration of risk management and value management in PPP projects, this paper attempts to examine the application of risk and value management practice in infrastructure development projects, predominantly in PPP projects, through semi-structured interviews conducted as a qualitative research methodology with ten industry practitioners. To achieve this aim, this paper attempts to identify the similarities between the two processes along with the benefits and critical success factors for the integration of RM and VM in PPP projects. The results suggest that, although risk and value management activities are said to be used in projects; "formal" RM and VM studies are rarely undertaken. The observations to date suggest that, although there are barriers against the integration of VM and RM, there is a need for the development of a systematic process to enable the integration of risk and value management to occur.
\end{abstract}

Keywords: Integration of Risk and Value Management, Public Private Partnership, Value for Money

\section{Introduction}

This paper presents the findings of a current doctoral research project on the integration of Risk Management (RM) and Value Management (VM) in Public Private Partnership (PPP) project management. The paper examines the application of risk and value management in infrastructure development projects, predominantly in PPP projects. As part of the research, a qualitative research methodology is adopted to identify the practice of, and the potential for integrating RM and VM in a single Study. To achieve this aim, semi-structured interviews were conducted with ten industry practitioners. The linkages between the two are examined and the paper identifies the similarities between RM and VM, the benefits of integration and the Critical Success Factors (CSF) for the integration of RM and VM. The research has identified that, while organisations contend to use RM and VM in project procurement processes, 'formal' RM and VM are rarely used. Furthermore, the results suggest that there is an increasing need for the integration of RM and VM, especially with new legislation such as the Australian 'Model Work Health and Safety Act' mandating the requirement to 'design out risk'. The final outcome is that it is highly desirable to formulate an Integrated Risk and Value Management (IRVM) framework for PPP projects. 


\section{Risk Management}

Standards Australia (2009, p.2) in its Risk Management Principles and Guidelines in AS/NZS ISO 31000:2009, Standard for Risk Management, defines RM as 'coordinated activities to direct and control an organisation with regard to risk' where a risk is 'effect of uncertainty on objectives". Similarly, the Project Management Institute in its, "A Guide to the Project Management Body of Knowledge' (PMBOK Guide) states, 'project RM includes the processes of conducting RM planning, identification, analysis, response planning, and monitoring and control on a project' (Project Management Institute 2008, p.273) RM is critical for successful project management as it enables key stakeholders to be aware of risks prior to decision making through the explicit identification, review and mitigating of these to minimize the impact of the risk (Abd-Karim et al. 2011).

According to Latham (1994) risk cannot be ignored as there is no risk free project and hence it needs to be accepted and managed accordingly by minimising, sharing or by transferring them. If there are potential benefits that can be gained by undertaking a risk that is a threat to the project, then that risk could be accepted and undertaken if it can be managed (Project Management Institute 2008). Likewise, effective RM can deliver better VfM in construction projects (Moonthanah, Poynter-Brown \& Jefferyes 1998). Over the years, with the maturing of RM methodologies, a number of frameworks, standards and guidelines have become readily available. Similarly, RM has become mandatory in the delivery of large infrastructure projects like PPP projects, where effective RM is the main driver of VfM in the project. Accordingly it is important to identify better ways of managing risk in PPP projects while at the same time looking at improving project value.

\section{Value Management}

The concept of VM originated from 'Value Analysis'. Lawrence D. Miles, a purchase engineer at the General Electric Company, New York, introduced Value Analysis (VA) in the 1940 s as a structured tactic in acquiring indispensable functions at the lowest cost and substantiate economic and technical viability of products in the United States manufacturing industry' (Male et al. 1998, pp.21-22). Since then the methodology has evolved. The systematic processes used in the appraisal of project functionality as a means of delivering effective project solutions are generally referred to as Value Planning (VP), Value Engineering (VE), Value Analysis (VA) and Value Management (VM). Although distinctions subsist in the terminology of VA, VE and VM, they are widely used interchangeably (Shen \& Liu 2003; Instiute of Value Management Australia 2012). There are numerous definitions used to describe VM in both academic literature and in industrial standards. The Australian Standard for Value Management AS 4183-2007, which originated as AS/NZS 4183:1994, is a well-regarded standard used by VM practitioners and defines VM as;

'a structured and analytical process in which a prescribed Work Plan is followed to achieve best value and, where appropriate value for money in products, processes, services, systems and organisations. The process may be applied to management decision making at any level of an organisation and is equally appropriate for public and private sector application' (Standards Australia 2007, p.iv).

The Australian Standard 4183-2007 acknowledges the approaches adopted by Miles in the 'Job Plan' approach and extends it to; a 'Work Plan' thereby referring to VM as the application of this 'Work Plan'. Additionally the standard encourages the use of VM methodology, along with other methodologies such as RM methodologies, to attain better VfM. Similarly, this paper looks at the potential for integrating these methodologies in a meaningful way. 


\section{RM and VM in Public Private Partnerships}

$\mathrm{RM}$ and $\mathrm{VM}$ are widely regarded as best practice methodologies in the successful delivery of projects through the allocation and management of risks amongst the consortiums of PPPs (Office of Government Commerce 2007; Al-Saleh \& Taleb 2010). Due to the significant benefits achieved by applying these methodologies when delivering projects, governments are increasingly mandating the use of these methodologies in the procurement of major infrastructure development projects; especially in PPP projects (Haghnegahdar \& Asgharizadeh 2008). Likewise, the Australian government has adopted the use of RM and VM methodologies in the procurement of PPP projects (Australian National Audit Office 2009; Queensland Department of Main Roads 2009). The endorsement of the United Kingdom's Office of Government Commerce (OGC) Gateway Review process in 2005 by the Australian government, which encourages the use of RM and VM in the Gateway Review process, signifies the importance of using them together as they are interrelated (Department of Finance and Administration 2006). Additionally, the Australian Standard for Value Management AS 4183-2007 (Standards Australia 2007) encourages the use of a RM component within VM Studies. This supports the notion of addressing risks in VM.

Due to the fundamental similarities between the two processes, the researchers have been advocating the integration of RM and VM (Latham 1994; Moonthanah, Poynter-Brown \& Jefferyes 1998; Green 2001; Hiley \& Paliokostas 2001; Clifford 2006; Dallas 2006a; Project Management Institute 2008; Cole et al. 2010). The contemporary evolution of both RM and VM when attempting to achieve 'explicit identification of the project objectives' when coupled with the autonomous practice of RM and VM often results in duplication of effort (Clifford 2006; Griffin \& Langdon 2006). The prevailing discourse advocates that the two should be integrated (Kirk 1995; Green 2001; Hiley \& Paliokostas 2001; Haghnegahdar \& Asgharizadeh 2008). Equally, despite the amount of literature promoting the benefits of integrating RM and VM in project management (Haghnegahdar \& Asgharizadeh 2008), limited attempts have been made to develop an IRVM framework in project management (Green 2001; Ellis, Wood \& Keel 2005; Dallas 2006b; Dikun \& Rahman 2010).

PPPs are primarily aimed at achieving VfM and enhanced service outcomes through proper:- 'risk transfer, encouraging innovation, greater asset utilisation and an integrated whole-of-life management, underpinned by private financing' (Infrastructure Australia 2008, p.3). While a significant link between risk and value exists in PPP projects, Dallas (2006c) argues that RM and VM needs to be integrated in order to optimise project value. Similarly, and mainly due to the lack of a proper framework integrating RM and VM in PPP projects, this research looks at how they could be integrated in a PPP project. This paper attempts to identify the factors that need to be address when developing an IRVM framework.

\section{Research Methodology}

This research is undertaken to elicit information on the integration of the RM and VM in a single Study. In order to gain a better understanding about the research topic, an extensive literature review was undertaken on RM, VM and PPP project management. In addition, and to obtain a broader industry perspective, practitioners of RM and VM involved in major infrastructure projects were interviewed. The aim of this qualitative-exploratory survey using interviews was to capture the status quo of RM and VM in current practice. According to Given (2008) interviews will enable the identification of the knowledge gap in both the literature and in practice through expert information gained within the industry.

In an attempt to facilitate open discussions, semi-structured interviews were used in the research. Teddlie and Tashakkori (2009) argue that interviewing is a powerful data collection tool and semi-structured interviews facilitate the asking of questions and the very nature of the one on one process makes it easier to elicit clear and unambiguous information between the interviewer and the interviewee. Accordingly interviews were conducted using a semi-

Ranesh, A. Zillante, G., and Chileshe, N. (2012) 'Towards the integration of risk and value management', Australasian Journal of Construction Economics and Building, Conference Series, 1 (2) 43-51 
structured interview instrument to facilitate for flexibility in asking questions and to gain an insight in to the research topic.

A homogeneous group of participants was invited to take part in the research because the research required the participants to have specific knowledge and experience in the area (Graziano \& Raulin 2004) of RM and VM in infrastructure development projects. Due to the lack of expert population in the industry a judgemental sampling method was used to identify the participants (Al-Saleh \& Taleb 2010). Respondents were recruited from those who had been directly involved in the decision making processes in infrastructure development projects. Participants were identified by first identifying in the major infrastructure development projects, especially in PPP projects and then identifying the key decision makers in the projects. Additionally, participants were identified using member directories of professional organisations related to RM and VM.

Selected practitioners and organisations were issued with a participant information sheet along with an invitation letter to take part in the research. Some organisations were reluctant to take part because the PPP nature of the research projects meant that they (the organisations) may have been in breach of client confidentiality. Against this limited availability of participants, consideration was given to sustaining a balance of opinion between public and private sector players when recruiting the interview participants.

A total of 51 invitations were sent out to participate in the research. Twelve agreed to participate but 2 participants later declined due to time constraints. Hence, a total of 10 interviews were conducted amongst industry practitioners. The interviews were conducted face-to-face and via telephone which lasted between 20 to 110 minutes. For this kind of research, a contrast between face-to-face and telephone interviews was not evident (Cole et al. 2010). To ensure the accuracy of analysis the interviews were tape-recorded (with their permission) and transcribed for analysis (Chung, Hensher \& Rose 2010). Due to the small number of interviews conducted, the use of sophisticated data analysis software's was considered unnecessary. Likewise, the data was analysed manually by identifying the themes with respect to research questions in the interview discussions. The interview instrument consisted of 27 questions divided in to 5 parts, covering:

1- Demographic information about the participants.

2- Awareness and practice of RM, VM, and VfM in PPP projects

3- Motive for integration

4- Integration of RM and VM in PPP projects

5- Implementation strategy

The interviews were aimed at identifying a clearer direction for the larger doctoral research project and the outcome of this interview data will be used to formulate a quantitative questionnaire survey to help quantify the initial findings.

\section{Interview Results}

The interviews were conducted amongst facilitators of RM and VM Studies and key decision makes of infrastructure development projects. Whilst the key aim was to investigate RM and VM practice, attention was given to recruiting individuals with experience in both the areas. However it was observed that there was a lack of experts with adequate knowledge in both areas of practice. Nevertheless, two of the independent facilitators had experience in conducting IRVM studies and were certified practitioners in both RM and VM from a professional body's perspective. Public and private sector organisations undertaking PPP projects were reluctant to take part in the research due to client confidentiality issues. Independent consultants, on the other hand were generally willing to take part in the

Ranesh, A. Zillante, G., and Chileshe, N. (2012) 'Towards the integration of risk and value management', Australasian Journal of Construction Economics and Building, Conference Series, 1 (2) 43-51 
research. The interviewees' experience in the industry ranged from 8 to over 40 years with an average of 20 years' experience in the industry.

Apart from one respondent, who had an undergraduate degree, all participants had postgraduate qualifications with one having a doctoral degree. It was also noted that all the participants were affiliated with a professional body of some nature with respect to their industry representation. Five participants were actually involved in more than one professional body.

Unlike, industry staff, independent facilitators tended to be more specialised in the use of RM and/or VM methodologies and were certified through their professional bodies. Formal education about project management or general management was common followed by formal education about RM. There was a clear lack however of formal education dealing with VM amongst the interviewees. Nevertheless, it was observed that many interviewees had generally undergone a self-education process with respect to $V M$, especially those practitioners who had pioneered VM in Australia. Accordingly, some of the participants had contributed to the development of the national standards dealing with RM and VM. Organisations that supported further Study encouraged their staff to become certified in formal RM and VM education. Interestingly some of these organisations were actually involved in the delivery of courses that were used to educate the RM and VM facilitators. It is also interesting to note that some Australian jurisdictions actually mandate the requirement for certified practitioner only to be allowed to conduct the RM and VM Studies.

Although the interview instrument was targeted to explore significant aspects of RM and VM industry practice this paper is limited to the following key areas:

\section{1- RM and VM practice in Australia \\ 2- Similarities between RM and VM \\ 3- Benefits of integration \\ 4- Critical Success Factors for integration}

\section{RM and VM Practice in Australia}

Interviewees revealed that RM and VM Studies are often carried out on their projects. These studies often start from the beginning of the project and go through all the different phases of the projects. It is common practice to have 1-2 day workshops for both RM and VM.

It was noted that while many organisations adopt the use of national standards about RM and VM it is common to modify or build upon these standards to suit the organisational needs or project nature. This is typically evident in larger organisations. Likewise, organisations engaged in the delivery of PPP projects use the national guidelines when procuring the projects which mandate the use of $\mathrm{RM}$ and $\mathrm{VM}$ in project delivery. While knowledge of RM methodology is generally acknowledged it was found that there is a lack of knowledge about VM standards among South Australian agencies responsible for delivering PPP projects. This was highlighted by a question about the Australian Standard for Value Management AS 4318/2007 which generally drew a blank don't know response. Their justification was that it was the responsibility of the agencies responsible for delivering the project to undertake the VM Studies and not the monitoring agencies. Yet it was evident that unlike other Australian jurisdictions, the South Australian government does not mandate the using of VM in the PPP procurement process and it is generally left to the agency responsible for the project to choose whether to choose to conduct VM Studies. Interestingly, this appears this to be in conflict with the Gateway Review process that actually mandates the use of RM and VM processes in the delivery of PPP projects.

It should be noted that the Gateway Review process adopted by the Australian government encourages the use of RM and VM in the delivery of infrastructure development projects 
(Department of Finance and Administration 2006). Likewise, the interviews revealed that for some Australian States, New South Wales; VM and RM are mandated. It was noted however that for New South Wales the RM and VM process is not formalised but rather often carried out via a tick box process by many organisations. Similarly, it was noted that the follow-up process after the Workshops and Studies was limited because the teams were too busy to go back and look at lessons learned.

It was also evident that the practice of RM and VM has matured to a point where some practitioners are encouraging the use of IRVM Studies for their projects and continuing to promote the practice of IRVM. Some experts suggested that with the similarities between the two and the added benefits that can be gained by applying IRVM Studies it is becoming more and more desirable to adopt an IRVM framework. The main argument put forward by the supporters of IRVM is that they provide a better return on investment though time and cost savings whilst enhancing project out comes.

\section{Similarities between RM and VM}

When the interviewees were asked about the similarities between RM and VM processes they all mentioned that they overlap each other and one respondent suggested that 'managing risk is managing value'. Similarly, a second interviewee elaborated on the similarity by saying that 'just put on a different hat' and continued to say 'we talk about risk now and talk about value tomorrow ... both must contribute to the VfM to the project'. A common argument put forward was that they involve exactly the same processes but with different focuses i.e. RM focuses on the negatives whilst VM focus on the positive.

When conducting the process, both RM and VM tend to employ the same group of people. Both require parties involved to be committed to an outcome. Another interviewee explained that 'both require participants to be informed about the circumstances, so they need to be familiar with it; and both benefit from having a facilitator to keep the discussion moving'. A participant in the research indicated that RM and VM are both structured decision making processes where the respective standards instruct how to follow a structured process to get the best outcomes. It was also noted that both use similar techniques such as brainstorming and function diagrams to conducting the studies.

\section{Benefits of Integration}

While both RM and VM require the same stakeholders to be involved in the delivery of the study, having an IRVM Study would lead to savings in people time to conduct the Studies. Nevertheless some argue that all people will not be needed all the time. Hence the Study facilitators would need to schedule the IRVM Study to take this into account and identify who should be involved in what stage of the Study. The similarities between the standards and processes that could be merged would help to save time during the studies. In doing this there is a need to maintain a focus on the individual areas which could easily be lost when the process is combined. The interviewees concern was that a loss of focus would result in a loss of understanding of the true purpose of the studies thereby resulting in confusion rather than clarity for the participants. Generally however it was felt that in addition to the direct time and cost savings that result because of integration, a combined study would also provide better Study outcomes. This is in turn would give the team the opportunity to assess the risk and its value components at the same time thereby increasing the potential for cost and value improvements whilst minimising duplication of effort.

An IRVM process facilitates an easier and simplified record maintenance process. It avoids the duplication of items in risk and value registers. People reviewing the reports will no longer need to engage in cross referencing during the evaluation process as there will only be one report required. Similarly, having an integrated Study process will enable open discussions between the risk and value teams. Communication amongst stakeholders will 
also be improved and this should lead to more open and transparent discussions and enable teams to identify their strengths and weaknesses much earlier in the process.

\section{Critical Success Factors for Integration}

In the attempt to integrate both RM and VM it is important to understand the factors that need to be considered to make the process successful. Accordingly, having a clear understating of the CSF for integration is important.

The research identified the following Critical Success Factors:
1- Type of Study
2- Methods used
3- Tools and techniques used
4- Selection of RM and VM standards to follow
5- Effective combination of individual RM and VM phases
6- Level of integration

The sceptics of IRVM argue that RM and VM should not me integrated. They argue that the integration of two separate disciplines that have been functioning in their own right would create confusion amongst Study participants and hamper the Study process. Hence a major challenge when integrating is to do it in a way that it is easy to follow and is less complex. This could be done by identifying the RM and VM processes that need to be integrated and at which stage of the project life cycle that integration should occur. In doing this and to ensure that the focus of the study participants is maintained attention needs to be given to the level of integration that needs to be made.

Moreover, in selecting the standards, tools and techniques that need to be used in the integrated study process, attention must be given to ensuring that they are matched with the study participants' knowledge base thereby ensuring a degree of familiarity and making the process easier to manage. The research suggests that the above CSFs need to be considered when developing an IRVM framework.

\section{Conclusion}

The research revealed that, although RM and VM activities are said to be used in projects; "formal" RM and VM Studies are rarely undertaken. The interview results suggest that, although there are barriers to the integration of $\mathrm{RM}$ and $\mathrm{VM}$, there is a need for the development of a systematic process to enable the integration of risk and value management to occur. When developing an IRVM framework it is also important to consider the CSFs that have been identified and the actual level of integration of the two processes and the phases that are integrated. The research findings suggest that the integration of RM and VM in a single study will provide with much needed cost and time savings in conducting the processes. In addition, proper application of an IRVM framework will facilitate to deliver better VfM for all stakeholders in major infrastructure development projects, especially in PPP projects.

While the aim of these exploratory interviews was to elicit information of the current practice the results will be used to develop a larger quantitative questionnaire survey. The phases and processes of RM and VM that need to be combined and the level of integration will be identified in the subsequent quantitative survey. Additionally attempts will be made to identify the appropriate tools and techniques that need to be used in the IRVM framework. This will assist in increasing the validity of the research. 


\section{References}

Abd-Karim, SB, Lowe, DJ, Abdul-Rahman, H, Wang, C, Yahya, IA \& Shen, GQ 2011, 'Integrating risk and value management using IRVM workshops: Case studies in infrastructure projects in UK', Scientific Research and Essays, vol. 6, no. 12, pp. 2470-2479.

Al-Saleh, YM \& Taleb, HM 2010, 'The integration of sustainability within value management practices: A study of experienced value managers in the GCC countries', Project Management Journal, vol. 41, no. 2, pp. 50-59.

Australian National Audit Office 2009, ANAO Audit Report No. 20 2008-09, Approval of Funding for Public Works, Commonwealth of Australia, Canberra, ACT.

Chung, D, Hensher, DA \& Rose, JM 2010, 'Toward the betterment of risk allocation: Investigating risk perceptions of Australian stakeholder groups to public-private-partnership toll road projects', Research in Transportation Economics, vol. 30, no. 1, pp. 43-58.

Clifford, B 2006, 'Improvement through cooperation - Integrating partnering, value management and risk management', One day seminar on 'Recent Developments in Project Management in Hong Kong', Hong Kong, pp. 6.1-6.8.

Cole, R, Burke, M, Leslie, E, Donald, M \& Owen, N 2010, 'Perceptions of representatives of public, private, and community sector institutions of the barriers and enablers for physically active transport', Transport Policy, vol. 17, no. 6, pp. 496-504.

Dallas, MF 2006a, 'Integrating value and risk management - the key to success', Delivering Value Today and Tomorrow, Brighton, UK, 14 -15 September.

Dallas, MF 2006b, Value and risk management: a guide to best practice, Blackwell Pub, Oxford.

Dallas, MF 2006c, 'Maximising project value through integrated risk and value management', Knowledge Bank, <http://www.value-eng.org/knowledge bank/attachments/200606.pdf>.

Department of Finance and Administration 2006, Guidance on the Gateway Review Process-A Project Assurance Methodology for the Australian Government, Asset Management Group, Department of Finance and Administration, Australian Government, Canberra.

Dikun, S \& Rahman, HZ 2010, 'The integration of value engineering and risk management in strategic alliance public private partnership', Value World, vol. 33, no. 2, pp. 44-53.

Ellis, RCT, Wood, GD \& Keel, DA 2005, 'Value management practices of leading UK cost consultants', Construction Management \& Economics, vol. 23, no. 5, pp. 483-493.

Given, LM (ed.) 2008, The Sage encyclopaedia of qualitative research methods, Sage Publications, Los Angeles, California.

Graziano, AM \& Raulin, ML 2004, Research methods: a process of inquiry (with student CD-ROM), 5th ed. edn, Pearson, Boston, MA.

Green, SD 2001, 'Towards an integrated script for risk and value management', International Project Management Journal, vol. 7, no. 1, pp. 52-58.

Griffin, L \& Langdon, D 2006, 'Taking Projects by S.T.O.R.M - A model for integrating value, opportunity and risk management', Value Magazine, vol. 15, no. 1, pp. 24-26.

Haghnegahdar, L \& Asgharizadeh, E 2008, 'The risk and value engineering structures and their integration with industrial projects management (A case study on I. K. Corporation)', Proceedings of World Academy of Science, Engineering and Technology, vol. 40, pp. 375-383.

Hiley, A \& Paliokostas, P 2001, 'Value management and risk management: an examination of the potential for their integration and acceptance as a combined management tool in the UK construction industry', COBRA, Cutting Edge and ROOTS conferences 2001 pp. 3-5.

Infrastructure Australia 2008, National Public Private Partnership: Policy Framework, Infrastructure Australia, Commonwealth of Australia,

Instiute of Value Management Australia 2012, Value Management - concept and application, viewed 2nd April, <http://www.value-management.com.au/a profile/a1.htm>.

Ranesh, A. Zillante, G., and Chileshe, N. (2012) 'Towards the integration of risk and value management', Australasian Journal of Construction Economics and Building, Conference Series, 1 (2) 43-51 
Kirk, DQ 1995, 'The integration of value management and risk management', SAVE Annual Proceedings pp. 62-70.

Latham, M 1994, Constructing the team, London, UK.

Male, S, Kelly, J, Fernie, S, Gronqvist, M \& Bowles, G 1998, Value management: the value management benchmark: Research results of an international benchmark study, Thomas Telford Publishing, London.

Moonthanah, DP, Poynter-Brown, R \& Jefferyes, M 1998, 'A strategy for managing project risk in value management studies', SAVE International Conference Proceedings 1998, pp. 266-274.

Office of Government Commerce 2007, Risk and value management; Achieving Excellence in Construction Procurement Guide: Procurement Guide 04, Office of Government Commerce, HM Treasury, London.

Project Management Institute 2008, A guide to the project management body of knowledge (PMBOK Guide) Fourth Edition, Project Management Institute Inc, Pennsylvania, USA.

Queensland Department of Main Roads 2009, Main Roads Project Delivery System, Engineering and Technology, Department of Main Roads, State of Queensland, Queensland.

Shen, Q \& Liu, G 2003, 'Critical Success Factors for Value Management Studies in Construction', Journal of Construction Engineering and Management, vol. 129, no. 5, pp. 485-491.

Standards Australia 2007, Australian Standard AS 4183-2007 - Value Management Standards Australia, Sydney, NSW.

Standards Australia 2009, Australian/New Zealand Standard AS/NZS ISO 31000:2009 Risk management_-Principles and guidelines, Standards Australia, Sydney, NSW.

Teddlie, C \& Tashakkori, A 2009, Foundations of mixed methods research: integrating quantitative and qualitative approaches in the social and behavioural sciences, Sage Publications, Thousand Oaks, California. 